\title{
Features of professional training of foreign students - future specialists in Russian philology by Russian universities
}

\author{
Olga Evdokimova ${ }^{1}$, Alena Ivanova $^{1}$, Anna Zakharova ${ }^{1, *}$, Tatyana Romanova $^{1}$, Nadezhda $_{\text {Fedorova }}{ }^{1}$ \\ ${ }^{1}$ Chuvash State University, 428017, Cheboksary, Russia
}

\begin{abstract}
The relevance of the study is due to the fact that for professional training of foreign philology students, a high level of knowledge of the Russian language is required. The article analyzes the work with foreign students studying Russian philology. The focus is on scientific circles dealing with the Russian language and Russian literature and creating conditions for socio-cultural adaptation and professional development. To increase knowledge of foreign students, a system of scientific circles designed to consolidate and deepen knowledge in Russian literature and language can be created. The article determines tasks of scientific circles, primary problems, features of teaching philological disciplines for foreign students. Based on authors' experience in teaching "Russian language (practical course)", "Basic language (theoretical course)", "History of Russian literature of the 10th-20th centuries", recommendations to enhance the role of additional education were developed; the relationship between the curricular and extracurricular activities was identified. It was concluded that scientific circles are aimed at forming those competencies whose development causes difficulties, but future specialists as professionals and representatives of the humanitarian sphere of life need them.
\end{abstract}

\section{Introduction}

In the context of globalization, strengthened economic, political and cultural ties with foreign countries, foreign students go to Russia to study the Russian language which is becoming popular as a means of communication in various fields of international communication and a language of specialty [1]. Due to the fact Russian philology is actualized abroad as a specialty, it is necessary to develop professional knowledge of Russian philology, since the demand for the Russian language intensifies. Insufficient knowledge of new forms and methods of teaching foreign students studying "Philology" in Russian universities makes the problem urgent.

Scientific literature on the stated problem has its own history and geography due to new realities of modern life. In modern methodological literature, the need for developing a cultural competence as a "means of comprehending the language and national culture" is emphasized [2]. As a result, foreign students have to develop linguistic and communicative competencies that ensure cultural and linguistic adaptation in the country. The Russian language is used as a means of obtaining professional knowledge.

Experience of working with foreign students shows difficulties that occur at the junction "the teaching specialty". The Russian language is studied during two stages: as a language of communication and as a language of specialty. The difference is significant.
Therefore, it is necessary to reinforce classes with additional teaching forms.

Based on the experience of working with foreign students at the faculty of Russian and Chuvash philology and journalism of the Chuvash State University named after I.N. Ulyanov, we developed the most general principles for the quality training of bachelors in conditions of forced bilingualism.

One of the main current challenges is dynamic development of the higher education system focused on the modernization of educational technologies and unification of the educational environment in the context of European and world integration. Higher education does not know geographical boundaries: students can study abroad, while foreign students can study at Russian universities. The number of foreign students has increased which puts forward new challenges for the teaching staff. An analysis of the research literature shows that the problem of training foreign philology students in Russia has become a priority. This problem is considered in various aspects: in terms of mentality and Russian national culture [3, 4], linguistic norms, spelling and punctuation literacy [5]. There are works devoted to the development of the Russian language as a language of specialty $[6,7]$.

The research interest in Russian literature as a means of solving complex problems of training foreign philology students is crucial [8].

Inter-discipline and trans-discipline relations relevant for teaching foreign students are studied as well.

* Corresponding author: zaharova_an@mail.ru 
One of the most important tasks of modernization and humanization of higher education is to achieve a high level of communicative readiness of university graduates; developed language skills are considered the most important; cognitive activities of foreign students should be expanded [9].

\section{Materials and methods}

The material and methods of research are determined by the purpose of teaching the Russian language and Russian literature to foreign students. Foreign students have insufficient knowledge of the Russian language and poor school preparation, since there is no continuity of a school-university educational system. A system approach that allows us to consider the training of foreign students as a system of interacting elements is used to analyze the potential of scientific circles in disciplines "Russian language" and "Russian literature", aimed at developing philological skills in working with text and building competencies that provide both social adaptation successful mastering of the profession, especially at the initial stage of the study.

The principles of the synergetic approach, according to which complex open systems are regarded as selforganizing, are used to study the evolution of favorable trends in teaching the Russian language and Russian literature. They contribute to the professional selfrealization of foreign students.

\section{Results}

It is well known that any language is learnt faster and more successfully in the process of active communication, however, it restricts the academic form of training for a number of reasons [10]. In order to adapt foreign students to the new socio-cultural and educational environment, as well as to overcome sociopsychological difficulties in the process of communication and acquisition of professional knowledge, extracurricular activities aimed at improving learning motivation can be implemented.

These forms are traditional, but their effectiveness has been confirmed at the beginning of the XXI century. It is a system of scientific circles united by a common goal. A single circle cannot solve the problem as a whole. Only a systematic, integrated approach can ensure the quality of training. In this regard, for foreign students studying Russian philology, circles are significant. The semantic load of these circles is different; they form the basis for the professional development.

\section{Discussion}

The Russian language is the basis of a specialty; literature is an essential component of professional knowledge and a ready-made sample of literary speech, a model of social and personal behaviour, as well as one of the sources of replenishment of Russian vocabulary.
Let us consider the interaction system of such scientific circles as "Russian Word" and "Russian Language in Interethnic Communication", whose work is unusually indicative, since it is continuous in the process of training. When students begin to study special subjects (the first year), the circle work pursues the immediate goals. First of all, philology students get acquainted with features of Russian culture, richness, originality and beauty of the Russian language. Linguistic and cultural adaptation is carried out by selecting texts which should contain background knowledge about Russian history, culture and life of the Russian people. Texts are not long, contain simple syntactic constructions and are accompanied by various tasks aimed at developing lexical, grammatical and text skills - abilities to choose a title, combine individual sentences into a single text, identify keywords, etc. [11].

Participants study spelling and punctuation rules. Difficulties in mastering literacy skills are associated with differences in grammatical systems of Russian and native languages (spelling of case endings of nouns and adjectives, distinguishing between hard and soft consonants, etc.). An effective way to enhance spelling and punctuation literacy is a phased work aimed at recognizing the need to select rules [12]. The circles allow students to solve a very difficult task: help learn rules, establish what fact of the language it relates to, develop literacy skills. Such work should be carried out throughout the learning process while studying various sections of the Russian language.

The problems of Russian pronunciation are considered separately. They are relevant for first-year foreign students. Insufficient knowledge of the Russian language makes it difficult to perceive written texts and learn new theoretical materials. For example, when studying phonetics and phonology, graphics and spelling, foreign students encounter difficulties associated with the use of hard and soft consonants, unpaired solid [ж], [ш] and [ц], pronunciation of some vowels ([ы]). Orthoepic norms should be learnt in parallel with the development of speech and literacy skills. Testing the pronunciation of an individual sound will be effective if the sound is considered as part of a syllable or a word, in comparison with other words having similar sounds, taking into account their spelling (correct pronunciation of two words, differentiation of the meanings of these words, making phrases or sentences with these words). These tasks take into account systemic connections of the language and develop speech skills.

Expansion of the vocabulary is crucial as well. Work with new words is required. It involves linguocultural analysis of words - etymology, lexical compatibility, selection of synonyms, antonyms and establishment of lexical parallels in the native language. Additional work aimed at identifying functions of words and stable expressions with a view to their appropriate use in speech [13] is required. Knowledge of equivalentlacking vocabulary, a custodian of cultural semantics, containing information important for the development of lexical skills is crucial [14]. To this end, regular work with linguistic dictionaries is required. 
Particular attention should be paid to the onomastic vocabulary which expands knowledge and helps study other philological disciplines. For example, students determine functions of literary anthroponyms included in the structure of a literary text or acting as headings; establishing the origin of personal names and surnames; identifying similarities and differences in the principles of nomination in Russian and native languages (cf., for example, Turkmen personal names Гарягды ("snow fell"), Ягмыр ("rain") and ancient Russian names Зима (winter), Мороз ("frost")).

Particular attention should be paid to the materials containing information on the dialogue of cultures of various peoples, their similarities and differences. The use of proverbs and sayings which are not only a source of information about history and culture, but a key to understanding national identity, allows us to establish things that unite peoples regardless of their ethnicity. Effective tasks are selection of stable expressions, identification of multilingual analogies. The task of determining meanings of proverbs and sayings which have similar meanings in a native language (Russian. You can't sit on two chairs; Turk. You can't hold two watermelons in one hand).

The study of terminological vocabulary causes great difficulties. Teaching philological disciplines requires knowledge of the main sections of the Russian language, scientific terminology, an ability to use lexical, phraseological and grammatical means in professional activities. It is important to take into account meanings of individual elements of scientific terms (for example, when explaining the meaning of the word lexicography, it is advisable to use terms vocabulary and graphics, give examples of other words with Greek roots $\lambda \varepsilon \xi$ iкó $\varsigma$ 'verbal' and $\gamma \rho \alpha ́(\varphi \omega$ 'write' - graphics, spelling, etc.).

The similar work in circles involves studies on Russian literature, since language and literature are two components of professional knowledge. In addition, it is also significant that in literary works national mentality is revealed. There are wide possibilities of establishing a dialogue of cultures which can contribute to knowledge professionalization.

The phased work allows students to create a holistic view of Russian literature, its aesthetic identity and moral values. The circle work on literature does not intend to cover all the material. Using examples from Russian classical literature, we can talk about literature of our country as a whole. The goal of the circle is to deepen knowledge about Russia, its history and culture, and to show the role of Russian classical literature in the world, to reveal originality of literary works by famous Russian writers and poets. Development of a holistic view of versatility of Russian literature is a crucial task.

At the initial training stage, students learn features of historical and literary development of Ancient Russia and the era of Enlightenment. Foreign students have poor knowledge of cultural, historical and social contexts [15]. Practical experience shows that it is really very difficult for foreign students, even taking into account auxiliary knowledge of history, to study foreign literature of a particular historical era. In our case, this is medieval literature created in the Old Slavonic language. Its translated version still requires special comments. The language barrier and the remoteness of the historical era are very significant factors that complicate an understanding of ancient Russian literature, its aesthetic features. Nevertheless, acquaintance with history of written Russian literature and its specific genres allows foreign students to form the most general idea of the origins of Russian literature.

Of course, even despite the language barrier, literature of the new ear is more understandable. It focuses on the human world in all its complexity and inconsistency. Foreign students compare heroes of Russian literature with those of native literature. It helps them find a common ground, see what unites people. As a result, the basis for mastering specialty as a whole is formed. A comparison identifies similarities and differences, opens up new approaches to the research subject. As part of the circle work, comparisons deepen the interest of foreign students in Russian literature as a subject of leisure and as a specialty.

This interest becomes stable when a world-famous artist is in the spotlight (e.g., the odes by M.V. Lomonosov).

Literature creates the most favourable conditions for the interaction of diverse types of knowledge, establishing interdisciplinary and transdisciplinary connections that contribute to an in-depth study of any discipline in general, the development of a systematic approach to the specialty. Transdisciplinarity is aimed at integrating the content and methods of disciplines, all other components of educational activities and is a condition for the formation of universal competencies, including developed verbal-logical thinking and general cultural training [16].

Classic odes by M.V. Lomonosov are an understandable and fertile material for gaining knowledge about Russia in its historical development. That is why the works by M.V. Lomonosov are studied during several classes. For example, Turkmen students tried to understand features of Russian versification using the Lomonosov's odes and compared them with versification in Turkmen poetry: they read poems, determined the poetic size, tried to compare the verses of Turkmen poets of the 19th - 20th centuries with the verses used by M.V. Lomonosov. Foreign students are interested in the ode parts where the poet tells about the large territory of Russia, its natural wealth, scientific and educational achievements. The geographical map of the European and Asian parts of Russia comes to life in poetic stanzas. As a result, Russian poetry of the 18th century becomes modern, and the works by M.V. Lomonosov become understandable.

Russian literature of the 19th century is studied as well. The names of A.S. Pushkin, N.V. Gogol, F.M. Dostoevsky, L.N. Tolstoy, A.P. Chekhov and many other Russian poets and writers are very familiar to foreign readers. In this regard, circle classes can take different forms: reading and learning by heart, interpretation and analysis, work with textbooks and research literature, presentations. The ultimate goal of the circle work is to speak at scientific and practical 
conferences. This is the level when a foreign student using acquired knowledge can build a monological statement on a given topic and compete with Russianspeaking students. The latter can be considered as a result of the systematic circle work on the Russian language and Russian literature.

\section{Conclusion}

As you know, pedagogical science recommends presenting educational material in a systematic way. The system of scientific circles should be considered as an obligatory part of the curriculum and implemented during the first and second training years. Foreign students are interested in group classes, as they understand that their competitiveness [17] in the labor market both depends on their knowledge of linguistic and speech literacy standards, cultural training, creativity of approaches, etc. This belief is formed in the process of everyday educational practice. During classes, foreign students learn to collect factual material for research. Its processing is a difficult task. Therefore, all students need help. To this end, they attend circle classes to establish relevance, theoretical and practical significance, novelty of the topic, formulate objectives, make a list of literature used, formulate written conclusions. An ability to build a written or oral monological statement on a professional or scientific topic is the highest achievement of a foreign student.

Modern research in the educational field has different directions. One of them is the development of an additional education system. Thus, showing the need for the independent analysis of multifaceted professional information, development of an ability to connect theoretical knowledge with practice, participation in joint activities, researchers emphasize the need and effectiveness of the additional education system for foreign students.

The circle work helps overcome the language barrier and update the positive experience of communication and acquired knowledge, create a favourable and creative environment, enhance learning motivation. The phased work allows students to differentiate the material in accordance with the curriculum, create the theoretical and practical base for the professional development and professionalization of knowledge.

Development of methods for teaching philological disciplines for foreign students can be a venue for further research. These methods should be aimed at developing independence and creativity of foreign students, application of educational technologies.

\section{References}

1. E.A. Kozhemyakova, S.I. Bakhtina, T.N. Pavlova, Pre-university stage of study in Russia and the world: language, adaptation, society, specialty: collection of articles of the I International Congress of Teachers and Heads of Preparatory Schools: in 2 parts. Peoples' Friendship University of Russia. Teaching the specialty language as the basis of professionally oriented training in the RCT system at the preuniversity stage. 1. 382-385. (2017).

2. E.V. Dishkant, Bulletin of the Northeast Federal University named after M.K. Ammosov. Series: Pedagogy. Psychology. Philosophy. Pedagogical aspects of the study of Russian national culture by foreign students. 1 (09). 5-13. (2018)

3. L.V. Borisova, Interethnic interaction in a multicultural educational space: problems of language interaction and intercultural communication: a collection of scientific articles based on the results of the All-Russian scientific and practical conference. Chuvash State Pedagogical University named after I. Ya. Yakovlev. To the question about the fauna code in the linguistic culture. 16-19. (2018).

4. E.A. Golubovskaya, N.V. Butylov, G.A. Khorokhorina, Education Integration. Studying the degree of influence of different methods of explication of ethnic stereotypes within the educational process. 22. 2. 290-310. (2018).

5. O.A. Lebedeva, Bulletin of Tomsk State University. Methodological principles of the formation of a sense of language in foreign philology students in the study of disciplines of the historical linguistic cycle. $\mathbf{3 2 2}$. 204 -206. (2009).

6. P.S. Bogdanova, V.G. Mehtiyev, Studia Humanitatis. Literature in teaching Russian students to the Russian language. 4. (2018).

7. A.V. Shchetinina, Scientific dialogue. On the problem of organizing additional education in the field of the Russian language as non-native. 2 (26): Pedagogy. 38-48. (2014).

8. E.N. Strelchuk, Bulletin of the Samara Scientific Center of the Russian Academy of Sciences. The role of fiction in the formation and development of Russian speech culture of foreign students. 13. 2 (5). 1135-1139. (2011).

9. A.A. Pozdnyakova, T.P. Chepkova, Cross Cultural Studies: Education and Science. International educational project "Preserving the culture in the language": concept, structure, forms of distance support. 3, III. 475-481. (2018).

10.I.L. Becker, S.A. Ivanchin, News of higher educational institutions. Volga region. Humanitarian sciences. Problems of adaptation of foreign students to the educational process of a Russian university (on the example of Penza State University). 4 (36). 247257. (2015).

11.T.N. Romanova, E.V. Chueva, Bulletin of the Chuvash University. Features of teaching the course "Russian language and the basics of creative writing" at the national university. 4. 290-296. (2018).

12.I.V. Gavrilova, Scientific and methodological electronic journal "Concept". On the issue of the 
formation of spelling and punctuation literacy of foreign students. 28. 16-18. (2017).

13.M.E. Petukhova, I.A. Simulina, Bulletin of the Chuvash University. Transformation of precedent texts as a phenomenon of modern Russian speech culture in the teaching of foreign-language communicants. 2. 212-217. (2015).

14.S.S. Khromov, M.N. Shutova, Bulletin of Perm Scientific Research Polytechnic University. Problems of linguistics and pedagogy. Interdisciplinary communication in the training of foreign philology students (during the internship at the Pushkin State Russian Language Institute). 3. 17-29. (2018).

15.A.S. Kurkina, Problems of teaching philological disciplines to foreign students: materials of the 4th International Scientific and Methodological Conference. Voronezh: CPI "Scientific Book". Organization of work on literary text with hidden meanings in a foreign audience. 291-296. (2016).
16.O.K. Evdokimova, V.I. Gorbunov, V.V. Andreev, A.M. Ivanova, A.N. Zakharova, International Conference "Topical Problems of Philology and Didactics: Interdisciplinary Approach in Humanities and Social Sciences" Advances in Social Science, Education and Humanities Research (ASSEHR). Methodology and Practice of Teaching of Philological Cycle Subjects at the Technical Faculties of Russian Universities. 312.464-469 (2018).

17.A. Zakharova, T. Talanova, G. Dulina, V. Semenov, I. Getskina, N. Semenova, The European Proceedings of Social \& Behavioural Sciences EpSBS. Psychological Features Of Competitiveness Of University Students. L. 1416-1423. doi:https://dx.doi.org/10.15405/epsbs.2018.12.173 (2018). 